\title{
Ion-implantation-caused special damage profiles determined by spectroscopic ellipsometry in crystalline and in relaxed (annealed) amorphous silicon
}

\author{
T. Lohner, M. Fried and J. Gyulai \\ Joint Chair for Experimental Physics of Technical University Budapest and KFKI Research Institute for Materials Science, \\ P.O. Box 49, H-1525 Budapest (Hungary)
}

K. Vedam and N. V. Nguyen

Materials Research Laboratory, Pennsylvania State University, University Park, PA 16802 (USA)

L. J. Hanekamp and A. van Silfhout

Faculty of Applied Physics, University of Twente, P.O. Box 217, 7500 AE Enschede (Netherlands)

\begin{abstract}
We previously developed a fitting method of several parameters to evaluate ion-implantation-caused damage profiles from spectroscopic ellipsometry (SE) (M. Fried et al., J. Appl. Phys., 71 (1992) 2835). Our optical model consists of a stack of layers with fixed and equal thicknesses and damage levels described by a depth profile function (coupled half Gaussians). The complex refractive index of each layer is calculated from the actual damage level by Bruggeman effective medium approximation (EMA) using crystalline (c-Si) and amorphous (a-Si) silicon as end-points. Two examples are presented of the use of this method with modified optical models. First, we investigated the surface damage formed by room temperature $\mathrm{B}^{+}$and $\mathrm{N}^{+}$implantation into silicon. For the analysis of the SE data we added a near surface amorphous layer to the model with variable thickness. Second, we determined $20 \mathrm{keV} \mathrm{B}^{+}$implantation-caused damage profiles in relaxed (annealed) amorphous silicon. In this special case, the complex refractive index of each layer was calculated from the actual damage level by the EMA using relaxed a-Si and implanted a-Si as end-points. The calculated profiles are compared with Monte Carlo simulations (TRIM code); good agreement is obtained.
\end{abstract}

\section{Introduction}

Surface disordering due to ion bombardment was observed in the case of light ions or high dose rates or elevated temperatures, for example $10 \mathrm{keV} \mathrm{B}^{+}[1]$, or at

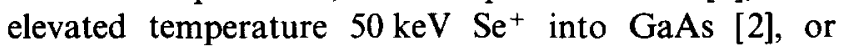
$50 \mathrm{keV} \mathrm{P}^{+}$into $\mathrm{Si}$ [3]. This phenomenon was previously shown in the case of boron implanted silicon by the combined application of single-wave ellipsometry and high-depth-resolution Rutherford backscattering spectrometry (RBS) $[4,5]$.

Several physical properties of a-Si are strongly influenced by both preparation procedure and thermal history. Unrelaxed a-Si films can be obtained by ion implantation (i-a-Si); fully relaxed films ( $\mathrm{r}-\mathrm{a}-\mathrm{Si})$ resulted from thermal treatment of $\mathrm{i}-\mathrm{a}-\mathrm{Si}$ at temperatures below the crystallization temperature $\left(<600^{\circ} \mathrm{C}\right)$ [6]. Otherwise, progressive transition from the $\mathrm{r}-\mathrm{a}-\mathrm{Si}$ to the i-a-Si can be obtained by low dose ion implantation which can be followed by optical methods [7]. The reimplantation-caused damage in $\mathrm{r}-\mathrm{a}-\mathrm{Si}$ can be made "visible" by Pd gettering [8].
The applicability of SE for the non-destructive determination of ion-implantation-induced damage profiles is demonstrated in detail in refs. [1,2,9-11].

\section{Experimental details}

To investigate the surface amorphization process, $200 \mathrm{keV}{ }^{14} \mathrm{~N}^{+}$or $10 \mathrm{keV}{ }^{11} \mathrm{~B}^{+}$ions were implanted at room temperature in $\langle 100\rangle$ silicon. The implantation was performed into Wacker-made single-crystal silicon. The implantation was conducted at room temperature with a current density of $190 \mathrm{nA} \mathrm{cm}{ }^{-2}$ for nitrogen and $0.5 \mu \mathrm{A} \mathrm{cm}^{-2}$ for boron.

To investigate the implantation-induced damage profile in relaxed silicon, amorphous silicon layers ( $\sim 800 \mathrm{~nm}$ thick) were produced by multiple-energy (100 keV-1 MeV) $\mathrm{Si}^{+}$implantation with a total dose of $10^{16}$ atoms $\mathrm{cm}^{-2}$ at room temperature. The samples were then annealed at $500{ }^{\circ} \mathrm{C}$ for $1 \mathrm{~h}$ in $\mathrm{N}_{2}$ to relax the a-Si fully. Intermediate states between $\mathrm{r}-\mathrm{a}-\mathrm{Si}$ and $\mathrm{i}-\mathrm{a}-\mathrm{Si}$ were made by reimplanting $B$ ions into the near surface 
at $20 \mathrm{keV}$ (projected range $50 \mathrm{~nm}$ ) with dose of 0.8 and $4 \times 10^{14} \mathrm{~B}^{+} \mathrm{cm}^{-2}$.

The SE spectra were obtained partly on a SOPRA rotating polarizer ellipsometer in the $1.5-4.5 \mathrm{eV}$ photon energy region in the range $300-650 \mathrm{~nm}$ with a rotating analyzer ellipsometer.

RBS and channeling techniques with $1.5 \mathrm{MeV}{ }^{4} \mathrm{He}^{+}$ ions were used to determine the radiation damage. The detector was placed to detect ions scattered through $97^{\circ}$ (with a glancing exit angle of $7^{\circ}$ to the surface). In this geometry, the depth resolution was better than $5 \mathrm{~nm}$ [12]. To evaluate the spectra we used the RBX program written by Kótai [13], which can also handle channeled spectra.

\section{Anomalous surface amorphization}

\section{1. $200 \mathrm{keV}$ nitrogen}

In this case the optical model consists of a native oxide layer, a thin amorphous silicon layer and a slightly damaged semiinfinite layer. For the evaluation, the $400 \mathrm{~nm}$ wavelength was chosen as an upper limit because in this case the optical penetration depth (even in crystalline $\mathrm{Si}$ ) is not greater than $200 \mathrm{~nm}$.

For the analysis of the spectroscopic ellipsometry data we used the conventional method of assuming appropriate optical models and fitting the model parameters (layer thicknesses and volume fractions of the amorphous silicon components in the layers) by linear regression. The data of the nitrogen-implanted samples were analyzed using a FORTRAN program. It is essential to choose a proper starting value for model parameters, otherwise the program can find a false minimum. We used grid search before the fitting. It was important that we used the complex dielectric function of implanted amorphous silicon [14].

Figure 1 shows the high-depth resolution RBS spectra (full size) and spectra recorded with a detector placed at scattering angle of $165^{\circ}$ (inset) for the series of nitrogen-implanted samples. In accordance with projected range calculations, significant buried disorder is observable around $400 \mathrm{~nm}$ depth (Fig. 1, inset). Surprisingly, the energetic nitrogen ions are shown to have created a well defined disorder at the very surface of silicon. The higher the dose, the larger is the disorder peak at the surface and the higher is the damage level in the first $200 \mathrm{~nm}$. For the study of this anomalous surface disorder (thin amorphous layer), SE is extremely useful because of its sensitivity.

Measured ellipsometric spectra of silicon samples implanted with different doses of nitrogen ions, together with the results of multiparameter fitting, are shown in Fig. 2. For comparison, a reference spectrum of virgin (unimplanted) silicon is also shown.

Table 1 summarizes the layer thickness values and damage levels that resulted from the evaluation of spectroellipsometric measurements. The agreement between SE calculations and RBS results is very good [15].

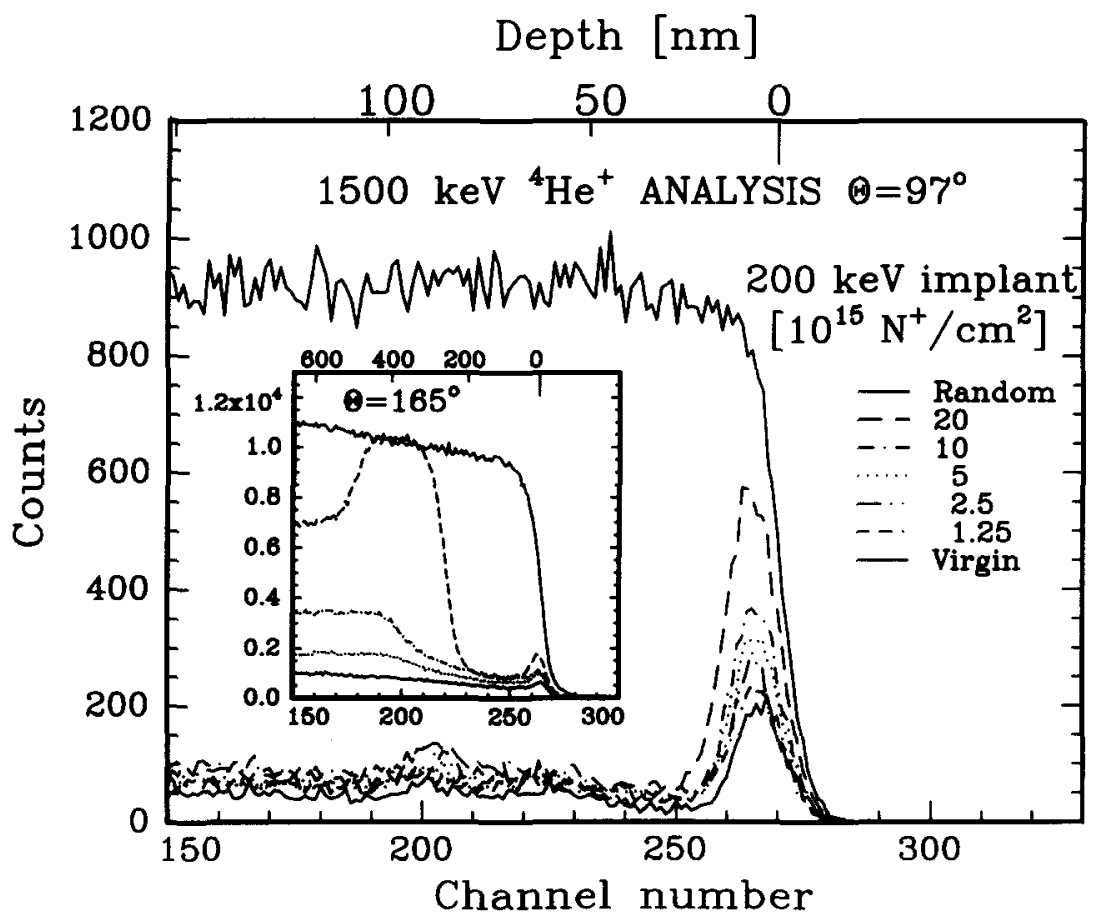

Fig. 1. High-depth resolution RBS spectra for the series of nitrogen-implanted samples: the inset shows the backscattering/channeling spectra recorded with the detector placed at a scattering angle of $165^{\circ}$. 


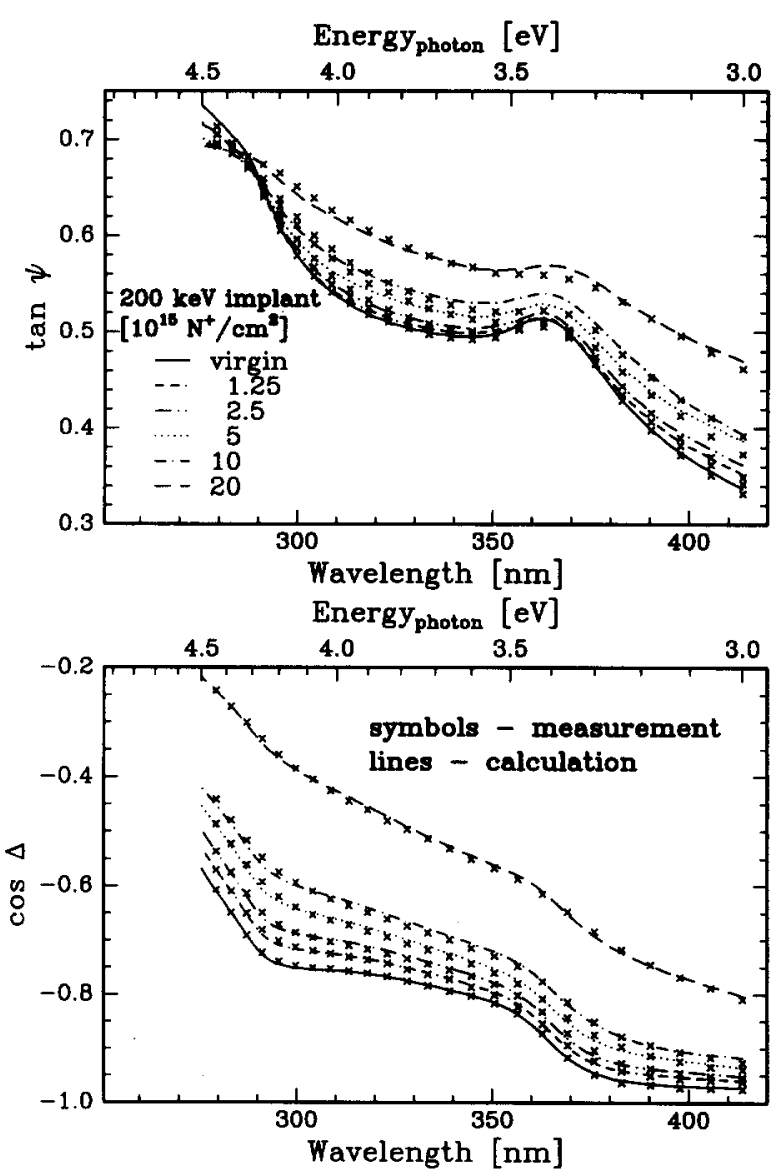

Fig. 2. Results of SE fitting for the nitrogen-implanted silicon samples: the angle of incidence was $70^{\circ}$.

TABLE 1. Implantation conditions and the results of the SE fitting procedure: nitrogen was implanted with $200 \mathrm{keV}$, boron with $10 \mathrm{keV}$; $\sigma$ is the unbiased estimator

\begin{tabular}{llllll}
\hline Ion & $\begin{array}{l}\text { Dose } \\
\left(10^{14} \mathrm{~cm}^{-2}\right)\end{array}$ & $\begin{array}{l}\text { Thickness } \\
\mathrm{a}-\mathrm{Si}(\mathrm{nm})\end{array}$ & $\begin{array}{l}\text { Damage } \\
\text { level }\end{array}$ & $\begin{array}{l}\text { Thickness } \\
\mathrm{SiO} \mathrm{O}_{2}(\mathrm{~nm})\end{array}$ & $\begin{array}{l}\sigma \\
\left(\times 10^{-2}\right)\end{array}$ \\
\hline${ }^{14} \mathrm{~N}^{+}$ & 12.5 & $0.7 \pm 0.1$ & $0.08 \pm 0.02$ & $2.0 \pm 0.1$ & 0.62 \\
${ }^{14} \mathrm{~N}^{+}$ & 25 & $1.0 \pm 0.2$ & $0.09 \pm 0.02$ & $2.2 \pm 0.2$ & 0.91 \\
${ }^{14} \mathrm{~N}^{+}$ & 50 & $2.3 \pm 0.3$ & $0.13 \pm 0.03$ & $2.0 \pm 0.2$ & 1.25 \\
${ }^{14} \mathrm{~N}^{+}$ & 100 & $3.1 \pm 0.2$ & $0.11 \pm 0.03$ & $2.3 \pm 0.2$ & 1.04 \\
${ }^{14} \mathrm{~N}^{+}$ & 200 & $7.0 \pm 0.3$ & $0.14 \pm 0.03$ & $4.8 \pm 0.2$ & 0.79 \\
${ }^{11} \mathrm{~B}^{+}$ & 4 & $1.9 \pm 0.4$ & See Fig. 3 & $1.5 \pm 0.2$ & 0.43 \\
${ }^{11} \mathrm{~B}^{+}$ & 8 & $4.5 \pm 0.8$ & See Fig. 3 & $2.0 \pm 0.2$ & 0.52 \\
${ }^{11} \mathrm{~B}^{+}$ & 18 & $26 \pm 2$ & See Fig. 3 & $2.2 \pm 0.2$ & 0.39 \\
\hline
\end{tabular}

\section{2. keV boron}

In this case the buried disorder peak is situated in the vicinity of the surface disorder because of the shorter projected range. To take account of this, one should apply the earlier developed optical model for damage depth profiling [11], which consists of a stack of films with fixed and equal thicknesses and damage levels determined by a depth profile function of coupled half-
Gaussians. The model uses five parameters: the center, the height and two standard deviations of the profile, and the thickness of the native oxide. For the present situation this model was enhanced with an added surface damage layer (beneath the native oxide) which is independent of the buried damage profile.

The measured ellipsometric parameters in the UV region (above $3.5 \mathrm{eV}$ where the optical absorption is high) predominantly contain information on the surface layer. At longer wavelength values the optical penetration depth is larger, and consequently the ellipsometric parameters in this range provide information mainly from deeper regions.

The results of best fitting and the experimental spectra are shown in Fig. 3. The inset illustrates the damage distribution extracted from the fitting procedure together with a Monte Carlo simulation (TRIM code [16]). The nominal values of layer thickness are given in Table 1.

For the interpretation of ion-bombardment induced epitaxial recrystallization and layer-by-layer amorphization, a model has been proposed by Nakata which takes

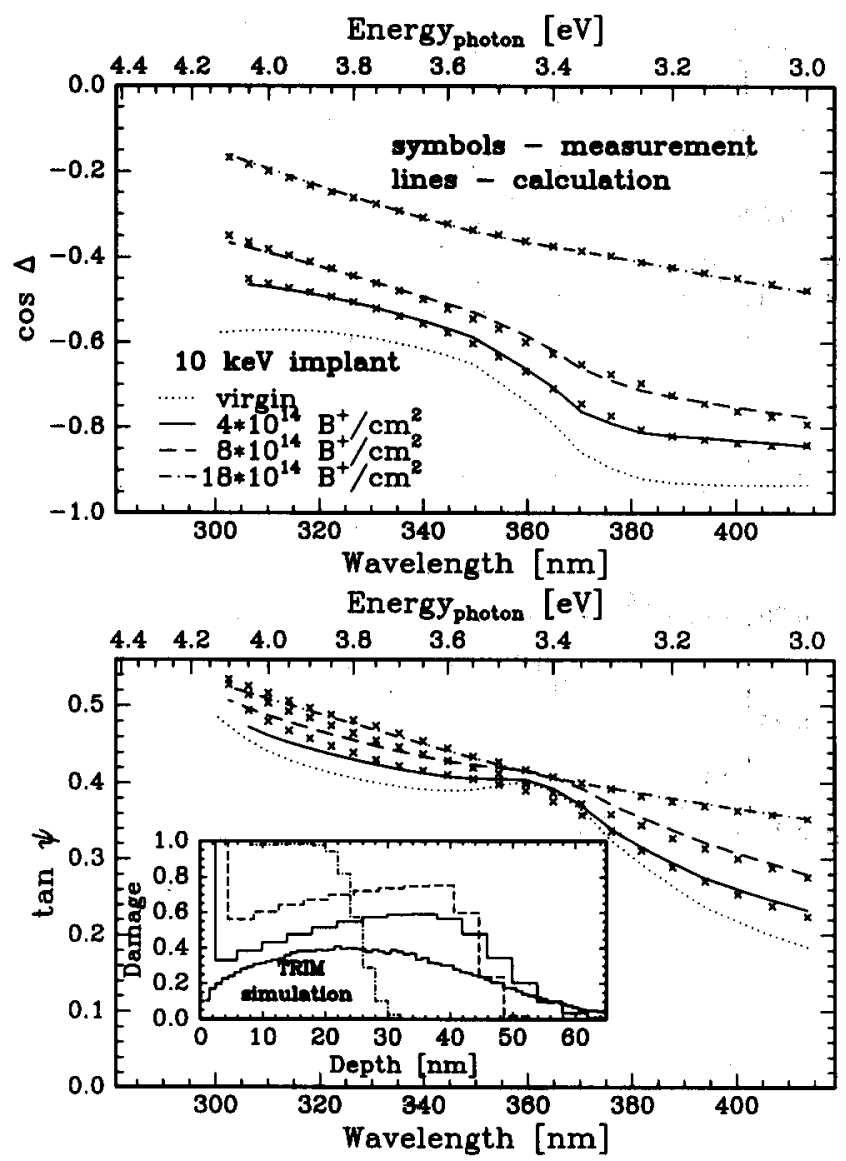

Fig. 3. Results of SE fitting for the $10 \mathrm{keV}$ boron implanted samples: the inset shows the damage profile deduced from the SE fitting, and the results of a TRIM simulation. 
account of the balance between the thermal diffusion of vacancies produced by nuclear scattering of incident ions and knocked-on interstitial silicon atoms that originated in the collisions caused by the same incident ions [17].

The mechanism of the surface amorphization process is discussed in relation to the ion beam induced layer-bylayer amorphization started at the silicon-native oxide interface in ref. 15.

\section{Reimplanted relaxed (annealed) amorphous silicon}

For the determination of $20 \mathrm{keV} \mathrm{B} \mathrm{B}^{+}$implantationcaused damage profiles in r-a-Si, the optical model based on the two coupled Gaussians was applied. In this special case, the complex refractive index of each layer was calculated from the actual damage level by the EMA using $\mathrm{r}-\mathrm{a}-\mathrm{Si}$ and $\mathrm{i}-\mathrm{a}-\mathrm{Si}$ as end-points. The experimental data and the fitted spectra are shown in Fig. 4. The calculated profiles are compared with

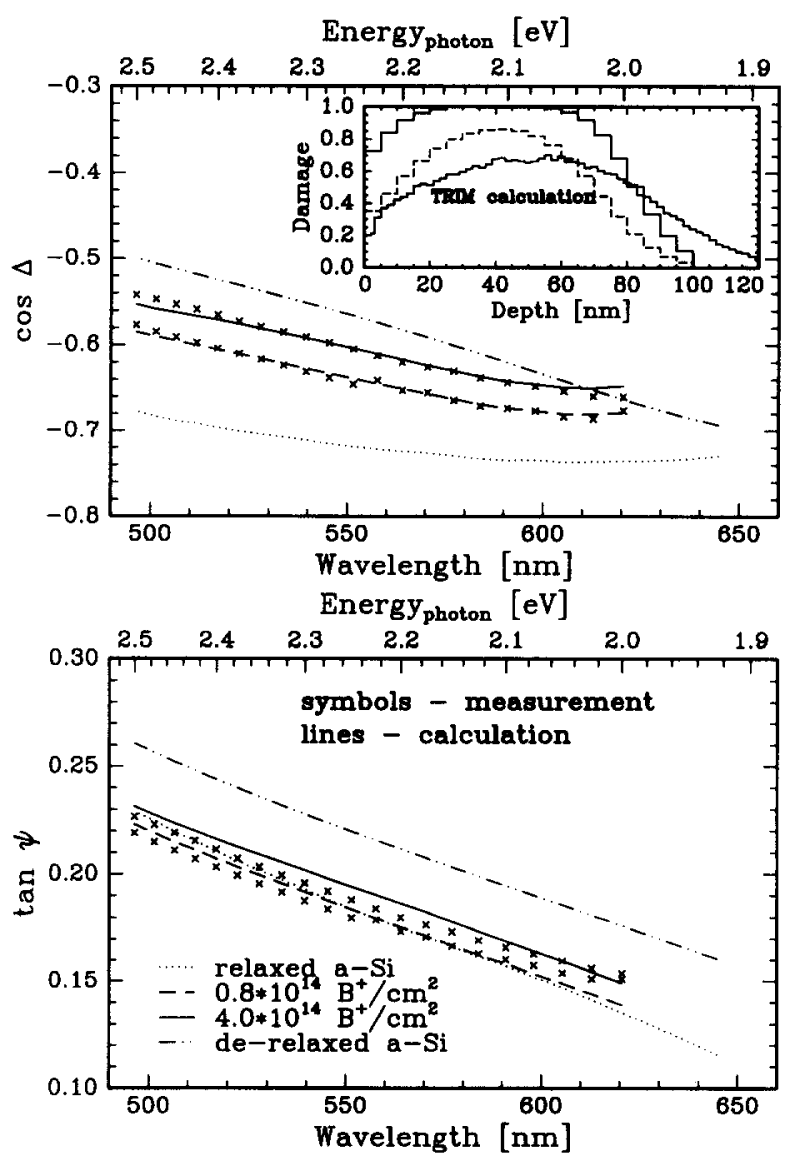

Fig. 4. Results for SE fitting for a $20 \mathrm{keV}$ boron reimplanted sample: the angle of incidence was set to $75^{\circ}$, near the pseudo-Brewster angle of a-Si; the inset shows the damage profile deduced from the $\mathrm{SE}$ fitting, and the results of a TRIM simulation.
Monte Carlo simulations (TRIM code) in the inset, and the profile shapes correspond well.

We attribute this reimplantation caused damage (de-relaxation) to beam-induced defects. Recent molecular dynamics studies of the relaxation of vacancies in amorphous silicon support this view [18].

\section{Conclusions}

Spectroscopic ellipsometry, high-depth-resolution Rutherford backscattering and channeling have been used to examine the surface damage formed by room temperature $\mathrm{B}^{+}$and $\mathrm{N}^{+}$implantation into silicon. A multiparameter fitting procedure of ellipsometric data was applied to evaluate the damage depth profile. It was found that the thickness of the surface-damaged silicon layer (beneath the native oxide layer) increased monotonously with increasing implantation dose.

The results demonstrate the applicability of spectroscopic ellipsometry together with proper optical model construction. RBS, as an independent cross-checking method, supported the constructed optical model.

We determined $20 \mathrm{keV} \mathrm{B}^{+}$implantation caused damage profiles in relaxed (annealed) amorphous silicon. The calculated profiles corresponded well to Monte Carlo simulations (TRIM code).

\section{Acknowledgments}

T. Lohner is grateful to IREX for a scholarship, and wishes to thank colleagues at the Pennsylvania State University for collaboration during his stay there. M. Fried is grateful to Twente University for a scholarship during his research work, and especially to N. Q. Khanh for performing RBS measurements. Partial support from OTKA grants (Nos. 3265 and F4378) is greatly appreciated.

\section{References}

1 M. Erman and J. B. Theeten, Surf. Interface Anal., 4 (1982) 98.

2 M. Erman and J. B. Theeten, Surf. Sci., 135 (1983) 353.

3 G. Q. Yang, N. Q. Khanh, M. Fried, E. Kótai, V. Schiller, L. C. Lu, J. Gyulai and S. C. Zou, Radiat. Eff. Def. Sol., 115 (1990) 183.

4 T. Lohner, G. Mezey, E. Kótai, F. Pászti, A. Manuaba and J. Gyulai, Nucl. Instr. Meth., 209/210 (1983) 615.

5 T. Lohner, E. Kótai, F. Pászti, A. Manuaba, M. Fried and J. Gyulai, J. Radioanal. Nucl. Chem., 83 (1) (1984) 75.

6 S. Roorda, W. C. Sinke, J. M. Poate, D. C. Jacobson, S. Dierker, B. S. Dennis, D. J. Eaglesham, F. Spaepen and P. Fuoss, Phys. Rev. B, 44 (1991) 3702 .

7 R. Reitano, M. G. Grimaldi, P. Baeri, E. Bellandi, A. Borghesi 
and G. Baratta, Materials Research Society Symp. Proc., Vol. 235, Materials Research Society, Pittsburgh, PA, 1992, p. 77.

8 S. Coffa, J. M. Poate, D. C. Jacobson and A. Polman, Appl. Phys. Lett., 58 (1991) 2916.

9 P. J. McMarr, K. Vedam and J. Narayan, J. Appl. Phys., 59 (1986) 694.

10 J. Vanhellemont, P. Roussel and H. E. Maes, Nucl. Instrum. Methods B, 55 (1991) 183.

11 M. Fried, T. Lohner, W. A. M. Aarnink, L. J. Hanekamp and A. van Silfhout, J. Appl. Phys., 71 (1992) 2835.
12 G. Mezey, E. Kótai, T. Lohner, T. Nagy, J. Gyulai and A. Manuaba, Nucl. Instrum. Methods, 149 (1978) 235.

13 E. Kotai, The RBX Code, unpublished work, 1984.

14 M. Fried, T. Lohner, W. A. M. Aarnink, L. J. Hanekamp and A. van Silfhout, J. Appl. Phys., 71 (1992) 5260.

$15 \mathrm{~T}$. Lohner et al., in the press.

16 J. F. Ziegler, J. P. Biersack and U. Littmark, The Stopping and Range of Ions in Solids, Pergamon, New York, 1985.

17 J. Nakata, Phys. Rev. B, 43 (1991) 14643.

18 R. Lutz and L. J. Lewis, Phys. Rev. B, in the press. 